\title{
biomolecules
}

ISSN 2218-273X

www.mdpi.com/journal/biomolecules/

Review

\section{Macrophage Expression of Inflammatory Genes in Response to EMCV Infection}

\author{
Zachary R. Shaheen and John A. Corbett * \\ Department of Biochemistry, Medical College of Wisconsin, 8701 W. Watertown Plank Rd, \\ Milwaukee, WI 53226, USA; E-Mail: zshaheen@mcw.edu \\ * Author to whom correspondence should be addressed; E-Mail: jcorbett@mcw.edu; \\ Tel.: +1-414-955-8768.
}

Academic Editor: Ivana Vancurova

Received: 16 June 2015 / Accepted: 8 August 2015 / Published: 18 August 2015

\begin{abstract}
The expression and production of type 1 interferon is the classic cellular response to virus infection. In addition to this antiviral response, virus infection also stimulates the production of proinflammatory mediators. In this review, the pathways controlling the induction of inflammatory genes and the roles that these inflammatory mediators contribute to host defense against viral pathogens will be discussed. Specific focus will be on the role of the chemokine receptor CCR5, as a signaling receptor controlling the activation of pathways leading to virus-induced inflammatory gene expression.
\end{abstract}

Keywords: inflammation, cytokine, virus, macrophage, diabetes, Ccr5

\section{Introduction}

Macrophages are a differentiated monocytic cell type within the innate immune system that have a well-defined role in the host response against viral infection [1,2]. Macrophages exert anti-viral effects through multiple mechanisms. They promote the removal and clearance of virally-infected cells, act as antigen presenting cells to shape the generation of an antigen-specific, adaptive immune response, and they express a range of effector molecules that promote anti-viral states and recruit other immune effectors to a local tissue environment. The macrophage responses to viral infection are important in the control and clearance of viruses, and have been described in detail by others $[1,2]$. In this review, the expression of inflammatory mediators which play a role in anti-viral immunity; specifically, 
the signaling mechanisms that regulate macrophage expression of inflammatory genes in response to viral infection will be addressed.

Macrophages express pattern recognition receptors (PRRs) that recognize foreign molecules (pathogen associated molecule patterns-PAMPs). The genetically inherited PRR families include Toll-like receptors (TLRs) and RIG-I-like receptors (RLRs) that recognize conserved structures that are specific to the type of pathogen (bacteria, virus, parasite) [3]. This recognition allows macrophages to produce a response that is selective for the PAMP.

For example, double stranded RNA (dsRNA), an intermediate formed during replication of many viruses, stimulates the production of anti-viral molecules including type I interferons (IFN) [3]. While significant progress has been made in identifying the PRRs that recognize PAMPS, and the pathways that control the selective innate immune responses to specific classes of invading pathogens, the importance of early and rapid induction of inflammation (chemokines, cytokines, lipid mediators and reactive oxygen and nitrogen species) in response to a specific class of pathogens, such as virus infection is not fully appreciated.

This review will focus on the activation of signaling cascades controlling the expression of the inflammatory genes interleukin (IL)-1, cyclooxygenase (COX)-2, and inducible nitric oxide synthase (iNOS) during virus infection in macrophages. The two isoforms of the pro-inflammatory cytokine IL-1 ( $\alpha$ and $\beta$ ) are primarily secreted by activated macrophages and regulate local and systemic responses to injury and infection, including virus infection [4,5]. Local IL-1 production promotes changes in vascular endothelium to increase access of effector cells to sites of infection, and contributes to local tissue destruction, while systemic IL-1 promotes fever [4,5]. Additionally, IL-1 regulates T-cell polarization [4-6] and plays a crucial role in the production of antibodies in response to pathogens or adjuvants [6,7]. Prostaglandins, produced by COX-2 during infection, are soluble factors that are secreted by activated macrophages and participate in the regulation of viral infection [8]. Similar to IL-1, the prostagladin $\mathrm{E}_{2}\left(\mathrm{PGE}_{2}\right)$ induces fever, promotes edema, and facilitates immune cell infiltration to sites of infection $[9,10]$. iNOS has been defined as an anti-viral inflammatory gene, because of its ability to attenuate the replication of multiple viruses [11-14]. Viral clearance is reduced and the incidence in mortality is increased in mice lacking iNOS in response to viral infection [15]. Nitric oxide's anti-viral effects may be explained, in part, by the S-nitrosation and inhibition of viral proteases [16], although this mechanism may not be generalizable to virus classes that do not require essential viral proteases to replicate. While IL-1, PGE2, and nitric oxide are all produced at high levels by macrophages following viral infection, these inflammatory mediators are not generally discussed as components of antiviral responses. The focus of this review will be on the mechanisms controlling the expression of IL-1 $\beta$, COX-2, and iNOS, in macrophages during virus infection.

\section{Encephalomyocarditis Virus (EMCV)}

The non-enveloped, positive single-stranded RNA picornavirus EMCV has been used for many years to elucidate anti-viral activities of virus infected cells [17]. Further, infection of genetically susceptible mouse strains [17-20] with EMCV results in diabetes development by two mechanisms. At low doses $(\leq 100 \mathrm{PFU}), \mathrm{EMCV}$-induced diabetes requires macrophage activation and inflammatory mediator production [21]. It is the production of inflammatory cytokines (IL-1 and TNF) that 
contribute to the loss of insulin producing $\beta$-cells and diabetes development [21]. Macrophage depletion with silica [22,23] or anti- Mac1 and Mac2 antibodies [24,25] attenuates EMCV-induced diabetes, while inhibition or ablation of adaptive immunity does not modify the incidence of diabetes in response to EMCV infection. Specifically, thymectomized mice or mice treated with anti-lymphocyte serum are not protected from EMCV-induced diabetes, and it is not possible to transfer diabetes to recipient mice using lymphocytes or spleen cells isolated from EMCV-induced diabetic mice [26]. Furthermore, EMCV-infected mice lacking T-cells (athymic) or B-cells $(\mu \mathrm{MT} / \mu \mathrm{MT}$ ) become hyperglycemic in a manner similar to EMCV-infected controls [27]. Furthermore, depletion of helper T-cells with $\mathrm{L}_{3} \mathrm{~T}_{4}$ antibodies and cytotoxic T-cells with Lyt2 antibodies does not modify diabetes incidence [24].

The mechanisms by which macrophages mediate the destruction of $\beta$-cells in EMCV-infected mice appear to be dependent on the production of inflammatory mediators. EMCV-induced diabetes in mice is attenuated by daily injection of neutralizing antibodies against the cytokines interleukin-1 (IL-1 $\beta$ ) or tumor necrosis factor (TNF- $\alpha$ ), or administration of aminoguanidine [28], a selective iNOS inhibitor [29,30]. In vitro studies using isolated rodent and human islets have shown that cytokines inhibit insulin secretion and kill $\beta$-cells by a mechanism that is associated with $\beta$-cell expression of iNOS and increased production of nitric oxide [31-37]. Because cytokines stimulate iNOS expression by $\beta$-cells [31-33], and EMCV-induced diabetes is attenuated by inhibitors of iNOS and antibodies that neutralize cytokines such as IL-1 and TNF [28], EMCV-induced diabetes is likely mediated by cytokine-stimulated iNOS expression and nitric oxide production by pancreatic $\beta$-cells that results in the loss of insulin secretion and $\beta$-cell viability. Consistent with this conclusion, EMCV-induced diabetes is attenuated in mice lacking iNOS [38]. These findings provide evidence to support a model in which inflammatory gene expression by activated macrophages contributes to the induction of diabetes following virus infection [39]. Inflammatory mediators, produced by macrophage, also participate in the development of diabetes in response to Kilham's Rat Virus (KRV) infection in the Bio-Breeding (BB) rat [40-43], the natural development of diabetes in the NOD mouse [44,45], and other models of diabetes [46-48]. Because of the importance of macrophage soluble mediator production (cytokines, nitric oxide, prostaglandins) in the development of virus-induced diabetes, the pathways controlling the production of these soluble mediators by macrophages in the context of EMCV infection will be discussed.

\section{Signaling Pathways Regulating Inflammatory Gene Expression in EMCV-Infected Macrophages}

The transcription factor nuclear factor kappa $\mathrm{B}(\mathrm{NF}-\kappa \mathrm{B})$ plays a central role in the regulation of inflammatory genes [49]. NF- $\mathrm{B}$ is normally held in the cytosol as an inactive dimer, bound to the inhibitory protein I $\mathrm{I} B \alpha$. Upon stimulation by pathogen associated molecular patterns (PAMPs), including Toll-Like Receptor (TLR) and double-stranded RNA (dsRNA) sensor ligands [3], I $\kappa \mathrm{B} \alpha$ is phosphorylated by Inhibitory Kappa Kinase (IKK). Phosphorylated $I \kappa B \alpha$ is targeted for degradation in a proteasomal-dependent manner, releasing $\mathrm{NF}-\kappa \mathrm{B}$ to translocate to the nucleus and initiate transcription [49]. NF- $\kappa$ B plays a primary role in activating the expression of inflammatory genes in macrophages in response to treatment with synthetic double-stranded RNA (dsRNA-polyI:C) or EMCV infection. PolyI:C and EMCV stimulate I $\mathrm{B}$ degradation, NF- $\kappa \mathrm{B}$ nuclear localization, and $N F-\kappa B$ reporter activation in macrophages. Inhibitors of $N F-\kappa B$ attenuate NF- $\kappa B$ nuclear localization 
and the expression of inflammatory genes IL-1 $\beta$, iNOS, and COX-2 in response to polyI:C and EMCV infection [50,51]. These findings are consistent with the known role of NF- $\kappa B$ in the regulation of iNOS [52,53], COX-2 [54,55], and IL-1 $\beta[56,57]$ transcriptional activation in response to other PAMPs, such bacterial endotoxin (lipopolysaccharide, LPS).

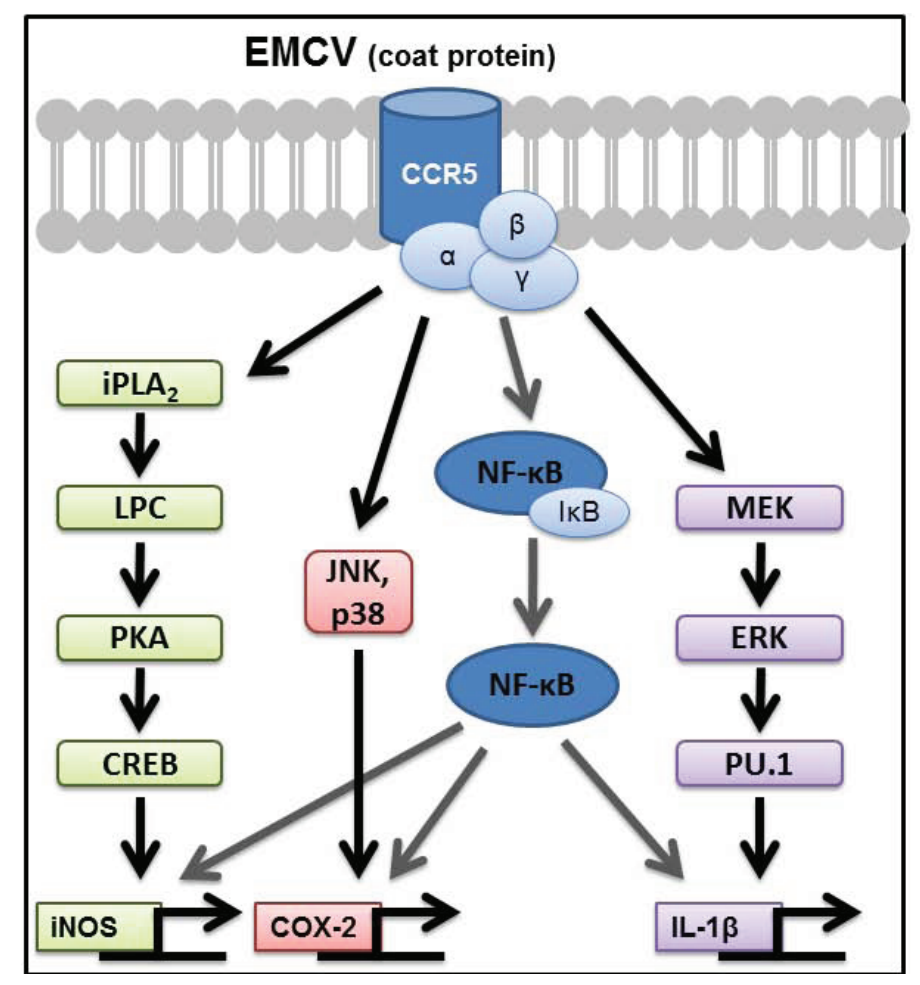

Figure 1. Signaling pathways required for encephalomyocarditis virus (EMCV) to stimulate pro-inflammatory gene expression in macrophages. The EMCV coat protein, devoid of viral RNA, activates CCR5-dependent signaling in macrophages within minutes of treatment. The transcription factor NF- $\mathrm{KB}$ is required for the expression of iNOS, COX-2, and IL-1 $\beta$, and at least one additional pathway that is selective for one of these target genes. iNOS expression is controlled by iPLA2 $\beta$ and occurs through PKA-dependent activation of the transcription factor CREB. COX-2 expression is controlled by the MAP kinases p38 and JNK, whereas IL-1 $\beta$ expression is controlled by the MAP kinase ERK and transcription factor PU.1.

In addition to NF- $\mathrm{NB}$, at least one secondary signaling pathway, selective for each target gene, is required for inflammatory gene expression by macrophages. These secondary signaling cascades include p38 and c-Jun N-terminal Kinase (JNK) for COX-2 expression [8,58], extracellular signal-regulated kinase (ERK) for IL-1 expression [59], and calcium independent phospholipase A2 (iPLA2 $\beta$ ) and cAMP response element-binding protein (CREB) for iNOS expression [60-62] in response to EMCV infection or treatment with dsRNA (summarized in Figure 1). These secondary signaling pathways are selective for the specific target genes, as inhibition of p38 and JNK prevent polyI:C- and EMCV-stimulated COX-2 expression without modifying IL-1 $\beta$ or iNOS expression in macrophages [58]. Likewise, inhibition of ERK attenuates IL-1 $\beta$ expression without modifying iNOS or COX-2 [58,59]. ERK likely regulates IL-1 $\beta$ transcription via the transcription factor PU.1, similar to previously published work 
demonstrating LPS-induced IL-1 $\beta$ expression in an ERK and PU.1-dependent manner [63-65]. Inhibitors of iPLA2 $\beta$ and CREB attenuate iNOS expression without modifying IL-1 or COX-2 expression [60-62]. The regulation of CREB activation in response to EMCV infection and polyI:C treatment requires iPLA2 $\beta$ and PKA activation, yet occurs by a cAMP-independent pathway. We have identified a novel mechanism by which products of PLA2 $\beta$ activate PKA-dependent signaling independent of changes in the intracellular concentrations of cAMP [61,62]. Consistent with our studies, Williams and Ford showed that iPLA2 $\beta$ stimulates PKA-dependent CREB activation by a phospholipid-dependent, cyclic nucleotide-independent mechanism [66], including in polyI:C treated bovine pulmonary artery endothelial cells [60]. Lysophospholipids are one product of PLA $2 \beta$ that may mediate PKA activation based on the ability of this lipid to reconstitute iNOS expression in PLA $2 \beta$ inhibited macrophages treated with polyI:C [61]. Overall, these findings emphasize the selectivity in pathways required for the activation of inflammatory genes in response to virus infection of macrophages (summarized in Figure 1).

\section{Additional Signaling Pathways That Contribute to the Regulation of Inflammatory Genes in EMCV-Infected Macrophages}

While polyI:C, EMCV, or LPS alone is sufficient to stimulate the expression of iNOS in RAW264.7 macrophages, a second signal, IFN- $\gamma$ is required to stimulate iNOS expression in naïve mouse macrophages [50,62]. IFN- $\gamma$ stimulates the expression of interferon regulatory factor-1 (IRF-1), a transcription factor required for the expression of iNOS [67]. While IFN- $\gamma$ is not required for polyI:C or EMCV-mediated COX-2 expression and production of prostaglandin $\mathrm{PGE}_{2}$, in the presence of IFN- $\gamma$, polyI:C and EMCV-stimulated COX-2 expression is enhanced in macrophages [51]. IL-1 $\beta$ expression in mouse macrophages occurs in response to polyI:C alone and is not enhanced by IFN- $\gamma$, although IFN- $\gamma$ appears to promote the release of biologically active IL-1 $\beta$ [50] in an IRF-1-independent manner [67]. In RAW264.7 macrophage cell lines, polyI:C and EMCV are sufficient to stimulate the expression of iNOS, COX-2, and IL-1 $\beta$ and IFN-Y enhances this response $[50,51,67]$.

In searching for mechanisms that would allow for the activation of each of the signaling cascades that selectively control the expression of inflammatory genes (iNOS, COX-2, and IL-1 $\beta$ ) in macrophages, we showed that pharmacological inhibitors and dominant negative mutants of the Src family kinases (SFKs) attenuate EMCV-stimulated expression of iNOS, COX-2, and IL-1 $\beta$ in macrophages [68]. SFKs are non-receptor tyrosine kinases that have been implicated in the expression of iNOS, cytokines IL-1 $\beta$ and TNF- $\alpha$, and COX-2 in response to LPS [69] and bacterial DNA (CpG) [70]. Inhibition of SFKs attenuates EMCV-stimulated I $\mathrm{B} \alpha \alpha$ degradation and phosphorylation of p38, but did not affect virus stimulated JNK or ERK phosphorylation [68]. These data suggest that SFKs regulate the expression of inflammatory genes, at least in part, through the activation of NF- $\kappa$ B. Consistent with a role of SFKs, Yoon and coworkers have shown that the SFK member Hck participates in the regulation of macrophage inflammatory genes in mice infected with EMCV [71].

One potential downstream target of SFKs is phosphoinositide-3 kinase (PI3K). PI3K is composed of an $85 \mathrm{kDa}$ regulatory subunit (p85) and a $100 \mathrm{kDa}$ catalytic subunit that when activated phosphorylates interior plasma membrane lipids [72]. These triphosphorylated inositide lipids serve as docking sites to promote the activation of signaling molecules that contain plekstrin homology (PH) domains. SFKs may 
promote $\mathrm{PI} 3 \mathrm{~K}$ activation through the $\mathrm{PI} 3 \mathrm{~K}$ regulatory subunit $\mathrm{SH} 2$ domain, which recognizes and binds to tyrosine-phosphorylation sites on SFKs, or through the two proline-rich regions on PI3K's regulatory subunit that could interact with the SH3 domains on SFK [73,74]. While the direct effects of EMCV infection on SFK-mediated PI3K activation has not been examined, PI3K inhibition (pharmacologically or by transfection with dominant negative PI3K) attenuates EMCV- and polyI:C-stimulated expression of iNOS, COX-2, and IL-1 $\beta$ in a manner similar to conditions of SFK inhibition [75]. The inhibition of PI3K in EMCV-infected macrophages also changes their morphology from an activated inflammatory phenotype to apoptosis and this shift in morphology is associated with elevated levels of caspase-3 activity [75]. Consistent with our observations, PI3K inhibitors cause macrophage apoptosis in response to parainfluenza virus infection [76]. It is interesting to speculate that PI3K may determine the phenotypic response of macrophages to virus infection. When PI3K is activated in response to virus infection, macrophage activation results in the production of inflammatory mediators to combat the infection; however, if PI3K is not activated, virus infection can result in macrophage apoptosis. In addition to macrophage activation, PI3K-dependent signaling participates in the establishment of latent and chronic viral infections in host cells [77,78]. The differences in responses are likely to be cell type and virus specific.

\section{Role of dsRNA Sensors in Response to Virus Infection}

Picornaviruses, including EMCV, are positive, single-stranded RNA viruses that form double-stranded RNA (dsRNA) when replicating their genome [17]. dsRNA sensors are a diverse group of Pattern Recognition Receptors (PRRs) that control cellular responses to virus infection. The principle response directed by dsRNA sensors is the induction of type I interferons (IFNs) [79]. In addition to type I IFNs, dsRNA sensors have been reported to regulate the activation of pro-inflammatory signaling pathways (including NF-kB) and the expression of cytokines [3].

There are a number of dsRNA sensors, each with unique subcellular locations and functions that are activated in response to EMCV infection and synthetic dsRNA (polyI:C) treatment. These receptors include toll-like receptor TLR-3, melanoma differentiation associated protein-5 (mda-5), retinoic acid-inducible gene (RIG-I), and protein kinase R (PKR), one of the first dsRNA sensors to be identified. PKR is a cytoplasmic eIF2 $\alpha$ kinase that is auto-phosphorylated following dsRNA binding and phosphorylates targets such as eIF2 $\alpha$ leading to the inhibition of translation initiation [80-82]. In addition to the phosphorylation of eIF $2 \alpha$, PKR participates in the regulation of additional signaling cascades in a cell type selective manner. Included in these cascades is the MAP kinases pathways and NF- $\kappa B$ [81]. TLR-3 is a dsRNA sensor that is localized to endosomes [83] and the retinoic acid-inducible gene like receptors (RLRs) mda-5 and RIG-I are localized to the cytoplasm. Mda-5 is the primary cytosolic dsRNA sensor that responds to long dsRNA, including polyI:C and EMCV viral genome, while RIG-I is not activated in response to EMCV or polyI:C and instead selectively responds to short dsRNA or uncapped ssRNA [84-86]. The primary role of each of these dsRNA sensors is to increase the production of type I IFNs and the induction of a classic type I IFN response to a virus infection or polyI:C treatment. While dsRNA sensors function in the induction of type I IFN in infected cells, they are dispensable for the activation of inflammatory gene expression by macrophages. Macrophages isolated from wild-type mice and mice deficient in mda-5 [87], TLR-3 [87], or PKR [51,59,61,88] 
express iNOS, COX-2, and IL-1 $\beta$ to equal levels in response to EMCV infection or polyI:C. Furthermore, the signaling cascades required for the expression of each of the inflammatory genes are activated to similar levels in macrophages isolated from wild-type mice or mice deficient in these dsRNA sensors [87,88]. Much like macrophages, PKR does not appear to participate in dsRNA- or EMCV-induced $\mathrm{I} \kappa \mathrm{B} \alpha$ degradation, NF- $\kappa \mathrm{B}$ nuclear localization, and NF- $\kappa \mathrm{B}$ promoter activity in $\mathrm{PKR}^{-/}$-deficient fibroblasts [89].

In contrast to the induction of inflammatory gene expression, dsRNA sensors are required for the induction of a type I IFN response to EMCV infection or polyI:C treatment. Macrophages lacking TLR-3 fail to express type I IFNs in response to polyI:C treatment and macrophages deficient in mda-5 fail to produce type I IFNs in response to EMCV infection [87]. Furthermore, in macrophages isolated from mice deficient in the type I IFN receptor (IFN $\alpha / \beta R$ ), expression of iNOS and IL-1 $\beta$ in response to EMCV infection is comparable to macrophages isolated from wild-type mice [88]. The type I IFN response is important for controlling virus infection, as titers of virus that accumulated in mice lacking dsRNA receptors are elevated and mortality increased following EMCV infection [90,91]. While these findings are consistent with the well-studied role of dsRNA sensors as a classic antiviral response, the importance of the dsRNA-independent induction of inflammatory genes in response to EMCV infection and polyI:C treatment as an antiviral response is unclear.

The induction of inflammatory gene expression in response to EMCV infection appears to be independent from the induction of the classical antiviral type I IFN response. Overall, the two responses do not temporally overlap, as EMCV rapidly activates the signaling cascade required for iNOS, COX-2 and IL-1 $\beta$ expression within minutes of infection, while EMCV RNA accumulation is a slow process first detectable 4-6 hours post infection in macrophages [88]. Furthermore, the accumulation of RNA is not required for EMCV-stimulated inflammatory gene expression by macrophages. We have shown that EMCV capsid protein devoid of viral RNA is sufficient to stimulate the activation of pro-inflammatory signaling cascades and the expression of iNOS, COX-2, and IL-1 $\beta$ expression to levels similar to unaltered EMCV $[87,88]$. Because EMCV capsid protein is sufficient to activate signaling within minutes of treatment it is likely that pro-inflammatory signaling occurs through the activation of a cell-surface receptor.

\section{CCR5 as the Signaling Receptor Responsible for Inflammatory Gene Expression in Response to EMCV Infection}

The chemokine receptor CCR5 is a cell-surface G protein-coupled receptor (GPCR) that is expressed in macrophages, lymphocytes, and dendritic cells [92]. Endogenous ligands for CCR5 that promote chemotaxis include the chemokine ligands $\mathrm{Ccl3}$, Ccl4, and Ccl5 (RANTES) [92-94]. CCR5 also functions as a co-receptor for macrophage-tropic HIV infection $[95,96]$ by interacting with gp 120 on the HIV envelope [97], and decreased CCR5 expression affords resistance to HIV infection [98,99]. Tyner and Holtzman have identified a role for CCR5 in promoting macrophage survival that is mediated by PI3K and MAPK activation during parainfluenza and influenza infection in mice [76]. We have shown that neutralization antibodies to CCR5 attenuate I $\mathrm{B} \alpha$ degradation, MAP kinase phosphorylation, and the expression of iNOS, COX-2, and IL-1 $\beta$ in EMCV-infected macrophages [87]. Consistent with CCR5 antibody neutralization, macrophages isolated from $\mathrm{CCR} 5^{-/-}$mice fail to express iNOS, COX-2, 
and IL-1 $\beta$ in response to EMCV infection (summarized in Figure 1). EMCV capsid protein, void of virus RNA, is sufficient to stimulate CCR5-dependent signaling and expression of inflammatory genes in macrophages [87]. Whereas CCR5 is required for the expression of inflammatory genes in response to EMCV infection of macrophages, CCR5 is not required for viral entry or replication, as EMCV RNA accumulates in infected macrophages harvested from $\mathrm{CCR} 5^{-/}$mice [87]. These observations are consistent with previous work demonstrating that adhesion molecules (likely VCAM-1) — and not CCR5 - are the likely viral-entry receptors for EMCV and other picornaviruses [100-103]. The induction of inflammatory genes in response to EMCV infection appears to function as an antiviral response, as virus RNA accumulates to levels eight-fold higher in macrophages isolated from $\mathrm{CCR}^{-/-}$mice compared to macrophages isolated from wild-type control mice infected with EMCV [87]. The enhanced accumulation of EMCV RNA in macrophages isolated from CCR5 deficient mice is also associated with increased expression of type I IFNs [87].

CCR5 is a promiscuous receptor that either binds directly to, or is activated by, multiple ligands. In addition to its role in regulating chemokine signaling in response to $\mathrm{Ccl} 3, \mathrm{Ccl} 4$, and $\mathrm{Ccl} 5$ (RANTES) [92-94], CCR5-dependent signaling is also activated by bacterial heat shock protein Hsp70 [104]. CCR5 controls a number of the effector functions of dendritic cells including the expression of IL-6 in response to virus infection [104] and functions as a co-receptor that facilitates HIV entry during infection [95,96] by interacting with the HIV envelope protein gp120 [97]. Macrophages also express iNOS and COX-2 in response to HIV infection [105,106], and gp120 is required for HIV-stimulated- $1 \beta$ expression by macrophages by a pathway that is dependent on CCR5, SFKs, and PI3K [107,108]. CCR5 is also a signaling receptor that maintains macrophage viability responses during influenza and parainfluenza infection [76]. These findings are consistent with a role for CCR5 as an integral cell surface receptor that participates in the activation of inflammatory cascades in macrophage in response to virus infection and suggest that CCR5 may function as a Pattern Recognition Receptor that participates in the rapid activation of an inflammatory response.

We hypothesize that CCR5 activation may function in an early and rapid response to infection, where virus coat protein or products of bacteria (such as hsp 70) trigger the induction of inflammatory genes such as iNOS, COX-2 and IL-1 $\beta$. The function of these gene products may be to inform neighboring cells that a pathogen is present (IL-1; [4,5]) resulting in the activation of pathways the limit infectivity or replication of the pathogen. This is known for nitric oxide [11-16] and prostaglandins [8-10,109] which inhibit virus replication. This affords cells in the vicinity of infection time to identify the pathogen and generate a more selective response based on the presence of a PAMP. In the case of virus infection, a dsRNA PRR would be activated and stimulate a type I IFN response [3,79,110,111]. This activation of dsRNA sensors that control the induction of type I IFNs does not require CCR5-dependent signaling $[87,88]$. In support of this hypothesis, we have shown that CCR5 does not participate in the induction of type I IFNs by virally infected macrophages, and that EMCV replication and the subsequent induction of type I IFNs is enhanced in mice lacking CCR5 [87].

\section{Conclusions}

The studies outlined in this review provide evidence that CCR5 functions as an integral cell surface signaling receptor that participates in signaling events leading to the expression of the inflammatory 
genes iNOS, COX-2, and IL-1 $\beta$ by macrophages in response to EMCV infection. This CCR5dependent response is activated within minutes of EMCV infection, and both temporally precedes and is mechanistically dissociated from the type I interferon response, which is not induced until hours later when EMCV RNA replication is detectable within macrophages (Figure 2). The activation of CCR5 by EMCV coat protein is consistent with the activation of this receptor by additional PAMPs from multiple virus classes and bacteria, which have been shown to stimulate CCR5-dependent responses. While this response does not appear to be a specific PRR/PAMP activated signaling cascade, activation of CCR5 signaling by EMCV coat protein appears to function as an anti-viral response. This cascade leads to an attenuation in the replication of EMCV allowing additional time for the innate immune systemt to generate a more specific PRR-dependent response that is selective to the type of infection, which in the case of virus infection results in the induction of type I interferons.

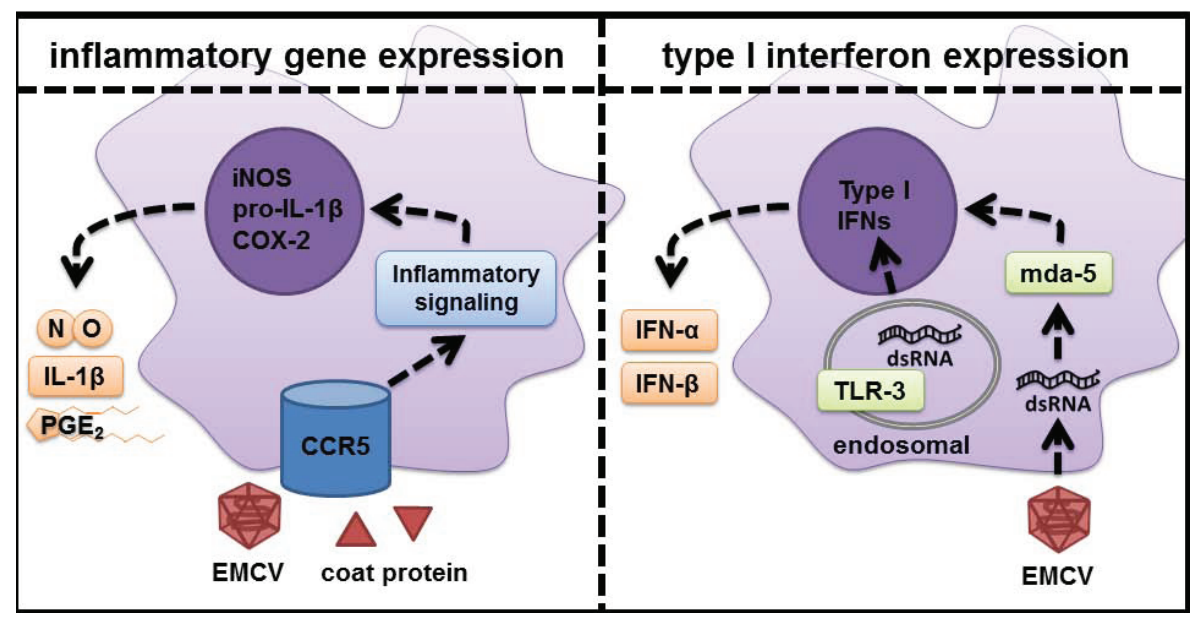

Figure 2. Differential responses of macrophages to EMCV infection. EMCV stimulates the activation of pro-inflammatory signaling within minutes and these pathways regulate the transcriptional activation of inflammatory genes (iNOS, COX-2, and IL-1 $\beta$ ) during viral infection. This pro-inflammatory response does not require the presence of dsRNA sensors or dsRNA sensor-dependent type I IFN production. It is hypothesized that this inflammatory cascade serves to maintain macrophage survival, limit replication of the pathogen, and to inform neighboring cells that a pathogen is in the vicinity. These events afford time for the innate immune response to identify the pathogen through a PRR and activate a more selective, secondary response that in the case of viral infection includes the expression and production of type I IFNs in response to viral dsRNA replicative intermediates.

\section{Acknowledgments}

The authors would like to thank Aaron Naatz, Jennifer McGraw, Bryndon Oleson, Kasia Broniowska, and Joshua Stafford for their help in proof-reading this manuscript. The authors would also like to thank all of the previous Corbett lab researchers whose work was described in detail in this review. This work was supported by grants from the NIH: DK-052194 and AI-44458 (to John A. Corbett). Zachary R. Shaheen was supported by F30 Fellowship DK102363-01A1 and a training grant from NIGMS T32-GM080202. 


\section{Author Contributions}

This manuscript was written and edited by Zachary Shaheen and John Corbett.

\section{Conflicts of Interest}

The authors declare no conflict of interest.

\section{References}

1. Aderem, A.; Underhill, D.M. Mechanisms of phagocytosis in macrophages. Ann. Rev. Immunol. 1999, 17, 593-623.

2. Janeway, C.A., Jr.; Medzhitov, R. Innate immune recognition. Ann. Rev. Immunol. 2002, 20, 197-216.

3. Takeuchi, O.; Akira, S. Pattern recognition receptors and inflammation. Cell 2010, 140, 805-820.

4. Dinarello, C.A. Interleukin-1 in the pathogenesis and treatment of inflammatory diseases. Blood 2011, 117, 3720-3732.

5. Dinarello, C.A. Immunological and inflammatory functions of the interleukin-1 family. Ann. Rev. Immunol. 2009, 27, 519-550.

6. Ben-Sasson, S.Z.; Hu-Li, J.; Quiel, J.; Cauchetaux, S.; Ratner, M.; Shapira, I.; Dinarello, C.A.; Paul, W.E. IL-1 acts directly on CD4 T cells to enhance their antigen-driven expansion and differentiation. Proc. Natl. Acad. Sci. USA 2009, 106, 7119-7124.

7. Marrack, P.; McKee, A.S.; Munks, M.W. Towards an understanding of the adjuvant action of aluminium. Nat. Rev. Immunol. 2009, 9, 287-293.

8. Steer, S.A.; Corbett, J.A. The role and regulation of COX-2 during viral infection. Viral Immunol. 2003, 16, 447-460.

9. Kalinski, P. Regulation of immune responses by prostaglandin E2. J. Immunol. 2012, 188, 21-28.

10. Harris, S.G.; Padilla, J.; Koumas, L.; Ray, D.; Phipps, R.P. Prostaglandins as modulators of immunity. Trends Immunol. 2002, 23, 144-150.

11. Karupiah, G.; Xie, Q.W.; Buller, R.M.; Nathan, C.; Duarte, C.; MacMicking, J.D. Inhibition of viral replication by interferon-gamma-induced nitric oxide synthase. Science 1993, 261, 1445-1448.

12. Sanders, S.P.; Siekierski, E.S.; Porter, J.D.; Richards, S.M.; Proud, D. Nitric oxide inhibits rhinovirus-induced cytokine production and viral replication in a human respiratory epithelial cell line. J. Virol. 1998, 72, 934-942.

13. Croen, K.D. Evidence for antiviral effect of nitric oxide. Inhibition of herpes simplex virus type 1 replication. J. Clin. Investig. 1993, 91, 2446-2452.

14. Mannick, J.B. The antiviral role of nitric oxide. Res. Immunol. 1995, 146, 693-697.

15. Flodstrom, M.; Horwitz, M.S.; Maday, A.; Balakrishna, D.; Rodriguez, E.; Sarvetnick, N. A critical role for inducible nitric oxide synthase in host survival following coxsackievirus B4 infection. Virology 2001, 281, 205-215. 
16. Saura, M.; Zaragoza, C.; McMillan, A.; Quick, R.A.; Hohenadl, C.; Lowenstein, J.M.; Lowenstein, C.J. An antiviral mechanism of nitric oxide: inhibition of a viral protease. Immunity 1999, 10, 21-28.

17. Carocci, M.; Bakkali-Kassimi, L. The encephalomyocarditis virus. Virulence 2012, 3, 351-367.

18. Craighead, J.E.; McLane, M.F. Diabetes mellitus: induction in mice by encephalomyocarditis virus. Science 1968, 162, 913-914.

19. Yoon, J.W.; Lesniak, M.A.; Fussganger, R.; Notkins, A.L. Genetic differences in susceptibility of pancreatic $\beta$ cells to virus-induced diabetes mellitus. Nature 1976, 264, 178-180.

20. Boucher, D.W.; Hayashi, K.; Rosenthal, J.; Notkins, A.L. Virus-induced diabetes mellitus. III. Influence of the sex and strain of the host. J. Infect. Dis. 1975, 131, 462-466.

21. Jun, H.S.; Yoon, J.W. The role of viruses in type I diabetes: Two distinct cellular and molecular pathogenic mechanisms of virus-induced diabetes in animals. Diabetologia 2001, 44, 271-285.

22. Baek, H.S.; Yoon, J.W. Role of macrophages in the pathogenesis of encephalomyocarditis virus-induced diabetes in mice. J. Virol. 1990, 64, 5708-5715.

23. Hirasawa, K.; Takeda, M.; Itagaki, S.; Doi, K. Involvement of macrophages in the development of encephalomyocarditis (EMC) virus-induced diabetes in mice. Exp. Anim. Jpn. Assoc. Lab. Anim. Sci. 1996, 45, 77-80.

24. Baek, H.S.; Yoon, J.W. Direct involvement of macrophages in destruction of $\beta$-cells leading to development of diabetes in virus-infected mice. Diabetes 1991, 40, 1586-1597.

25. Hirasawa, K.; Tsutsui, S.; Takeda, M.; Mizutani, M.; Itagaki, S.; Doi, K. Depletion of Mac1-positive macrophages protects DBA/2 mice from encephalomyocarditis virus-induced myocarditis and diabetes. J. Gen. Virol. 1996, 77, 737-741.

26. Yoon, J.W.; McClintock, P.R.; Bachurski, C.J.; Longstreth, J.D.; Notkins, A.L. Virus-induced diabetes mellitus. No evidence for immune mechanisms in the destruction of $\beta$-cells by the D-variant of encephalomyocarditis virus. Diabetes 1985, 34, 922-925.

27. Kounoue, E.; Izumi, K.; Ogawa, S.; Kondo, S.; Katsuta, H.; Akashi, T.; Niho, Y.; Harada, M.; Tamiya, S.; Kurisaki, H.; et al. The significance of T cells, B cells, antibodies and macrophages against encephalomyocarditis (EMC)-D virus-induced diabetes in mice. Arch. Virol. 2008, 153, 1223-1231.

28. Hirasawa, K.; Jun, H.S.; Maeda, K.; Kawaguchi, Y.; Itagaki, S.; Mikami, T.; Baek, H.S.; Doi, K.; Yoon, J.W. Possible role of macrophage-derived soluble mediators in the pathogenesis of encephalomyocarditis virus-induced diabetes in mice. J. Virol. 1997, 71, 4024-4031.

29. Corbett, J.A.; Tilton, R.G.; Chang, K.; Hasan, K.S.; Ido, Y.; Wang, J.L.; Sweetland, M.A.; Lancaster, J.R., Jr.; Williamson, J.R.; McDaniel, M.L. Aminoguanidine, a novel inhibitor of nitric oxide formation, prevents diabetic vascular dysfunction. Diabetes 1992, 41, 552-556.

30. Corbett, J.A.; McDaniel, M.L. The use of aminoguanidine, a selective iNOS inhibitor, to evaluate the role of nitric oxide in the development of autoimmune diabetes. Methods 1996, 10, 21-30.

31. Corbett, J.A.; Lancaster, J.R., Jr.; Sweetland, M.A.; McDaniel, M.L. Interleukin-1 $\beta$-induced formation of EPR-detectable iron-nitrosyl complexes in islets of Langerhans. Role of nitric oxide in interleukin-1 $\beta$-induced inhibition of insulin secretion. J. Biol. Chem. 1991, 266, 21351-21354. 
32. Southern, C.; Schulster, D.; Green, I.C. Inhibition of insulin secretion by interleukin-1 $\beta$ and tumour necrosis factor- $\alpha$ via an L-arginine-dependent nitric oxide generating mechanism. FEBS Lett. 1990, 276, 42-44.

33. Welsh, N.; Eizirik, D.L.; Bendtzen, K.; Sandler, S. Interleukin-1 $\beta$-induced nitric oxide production in isolated rat pancreatic islets requires gene transcription and may lead to inhibition of the Krebs cycle enzyme aconitase. Endocrinology 1991, 129, 3167-3173.

34. Mandrup-Poulsen, T. The role of interleukin-1 in the pathogenesis of IDDM. Diabetologia 1996, 39, 1005-1029.

35. Corbett, J.A.; McDaniel, M.L. Intraislet release of interleukin 1 inhibits $\beta$ cell function by inducing $\beta$ cell expression of inducible nitric oxide synthase. J. Exp. Med. 1995, 181, 559-568.

36. Arnush, M.; Heitmeier, M.R.; Scarim, A.L.; Marino, M.H.; Manning, P.T.; Corbett, J.A. IL-1 produced and released endogenously within human islets inhibits $\beta$ cell function. J. Clin. Investig. 1998, 102, 516-526.

37. Arnush, M.; Scarim, A.L.; Heitmeier, M.R.; Kelly, C.B.; Corbett, J.A. Potential role of resident islet macrophage activation in the initiation of autoimmune diabetes. J. Immunol. 1998, 160, 2684-2691.

38. Lee, Y.S.; Li, N.; Shin, S.; Jun, H.S. Role of nitric oxide in the pathogenesis of encephalomyocarditis virus-induced diabetes in mice. J. Virol. 2009, 83, 8004-8011.

39. Lacy, P.E. The intraislet macrophage and type I diabetes. Mt. Sinai J. Med. N. Y. 1994, 61, 170-174.

40. Chung, Y.H.; Jun, H.S.; Kang, Y.; Hirasawa, K.; Lee, B.R.; van Rooijen, N.; Yoon, J.W. Role of macrophages and macrophage-derived cytokines in the pathogenesis of Kilham rat virus-induced autoimmune diabetes in diabetes-resistant BioBreeding rats. J. Immunol. 1997, 159, 466-471.

41. Ellerman, K.E.; Richards, C.A.; Guberski, D.L.; Shek, W.R.; Like, A.A. Kilham rat triggers T-cell-dependent autoimmune diabetes in multiple strains of rat. Diabetes 1996, 45, 557-562.

42. Guberski, D.L.; Thomas, V.A.; Shek, W.R.; Like, A.A.; Handler, E.S.; Rossini, A.A.; Wallace, J.E.; Welsh, R.M. Induction of type I diabetes by Kilham's rat virus in diabetes-resistant BB/Wor rats. Science 1991, 254, 1010-1013.

43. Mendez, I.I.; Chung, Y.H., II; Jun, H.S.; Yoon, J.W. Immunoregulatory role of nitric oxide in Kilham rat virus-induced autoimmune diabetes in DR-BB rats. J. Immunol. 2004, 173, 1327-1335.

44. Jun, H.S.; Yoon, C.S.; Zbytnuik, L.; van Rooijen, N.; Yoon, J.W. The role of macrophages in T cell-mediated autoimmune diabetes in nonobese diabetic mice. J. Exp. Med. 1999, 189, 347-358.

45. Jun, H.S.; Santamaria, P.; Lim, H.W.; Zhang, M.L.; Yoon, J.W. Absolute requirement of macrophages for the development and activation of $\beta$-cell cytotoxic $\mathrm{CD}^{+} \mathrm{T}$-cells in T-cell receptor transgenic NOD mice. Diabetes 1999, 48, 34-42.

46. Lefkowith, J.; Schreiner, G.; Cormier, J.; Handler, E.S.; Driscoll, H.K.; Greiner, D.; Mordes, J.P.; Rossini, A.A. Prevention of diabetes in the BB rat by essential fatty acid deficiency. Relationship between physiological and biochemical changes. J. Exp. Med. 1990, 171, 729-743.

47. Oschilewski, U.; Kiesel, U.; Kolb, H. Administration of silica prevents diabetes in BB-rats. Diabetes 1985, 34, 197-199.

48. Wright, J.R., Jr.; Lefkowith, J.B.; Schreiner, G.; Lacy, P.E. Essential fatty acid deficiency prevents multiple low-dose streptozotocin-induced diabetes in CD-1 mice. Proc. Natl. Acad. Sci. USA 1988, 85, 6137-6141. 


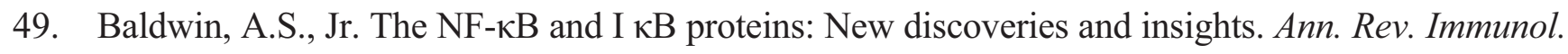
1996, 14, 649-683.

50. Heitmeier, M.R.; Scarim, A.L.; Corbett, J.A. Double-stranded RNA-induced inducible nitric-oxide synthase expression and interleukin-1 release by murine macrophages requires NF- $\kappa \mathrm{B}$ activation. J. Biol. Chem. 1998, 273, 15301-15307.

51. Steer, S.A.; Moran, J.M.; Maggi, L.B., Jr.; Buller, R.M.; Perlman, H.; Corbett, J.A. Regulation of cyclooxygenase- 2 expression by macrophages in response to double-stranded RNA and viral infection. J. Immunol. 2003, 170, 1070-1076.

52. Kim, H.; Lee, H.S.; Chang, K.T.; Ko, T.H.; Baek, K.J.; Kwon, N.S. Chloromethyl ketones block induction of nitric oxide synthase in murine macrophages by preventing activation of nuclear factor-кB. J. Immunol. 1995, 154, 4741-4748.

53. Mulsch, A.; Schray-Utz, B.; Mordvintcev, P.I.; Hauschildt, S.; Busse, R. Diethyldithiocarbamate inhibits induction of macrophage NO synthase. FEBS Lett. 1993, 321, 215-218.

54. Chen, C.C.; Sun, Y.T.; Chen, J.J.; Chiu, K.T. TNF- $\alpha$-induced cyclooxygenase-2 expression in human lung epithelial cells: Involvement of the phospholipase C-gamma 2, protein kinase C- $\alpha$, tyrosine kinase, NF-кB-inducing kinase, and I-kappa B kinase 1/2 pathway. J. Immunol. 2000, $165,2719-2728$.

55. Hwang, D.; Jang, B.C.; Yu, G.; Boudreau, M. Expression of mitogen-inducible cyclooxygenase induced by lipopolysaccharide: Mediation through both mitogen-activated protein kinase and NF-кB signaling pathways in macrophages. Biochem. Pharmacol. 1997, 54, 87-96.

56. Hiscott, J.; Marois, J.; Garoufalis, J.; D’Addario, M.; Roulston, A.; Kwan, I.; Pepin, N.; Lacoste, J.; Nguyen, H.; Bensi, G.; et al. Characterization of a functional NF-кB site in the human interleukin 1 $\beta$ promoter: Evidence for a positive autoregulatory loop. Mol. Cell. Biol. 1993, 13, 6231-6240.

57. Cogswell, J.P.; Godlevski, M.M.; Wisely, G.B.; Clay, W.C.; Leesnitzer, L.M.; Ways, J.P.; Gray, J.G. NF- $\kappa$ B regulates IL-1 $\beta$ transcription through a consensus NF- $\kappa B$ binding site and a nonconsensus CRE-like site. J. Immunol. 1994, 153, 712-723.

58. Steer, S.A.; Moran, J.M.; Christmann, B.S.; Maggi, L.B., Jr.; Corbett, J.A. Role of MAPK in the regulation of double-stranded RNA- and encephalomyocarditis virus-induced cyclooxygenase-2 expression by macrophages. J. Immunol. 2006, 177, 3413-3420.

59. Maggi, L.B., Jr.; Moran, J.M.; Buller, R.M.; Corbett, J.A. ERK activation is required for double-stranded RNA- and virus-induced interleukin-1 expression by macrophages. J. Biol. Chem. 2003, 278, 16683-16689.

60. Martinson, B.D.; Albert, C.J.; Corbett, J.A.; Wysolmerski, R.B.; Ford, D.A. Calcium-independent phospholipase A2 mediates CREB phosphorylation in double-stranded RNA-stimulated endothelial cells. J. Lipid Res. 2003, 44, 1686-1691.

61. Maggi, L.B., Jr.; Moran, J.M.; Scarim, A.L.; Ford, D.A.; Yoon, J.W.; McHowat, J.; Buller, R.M.; Corbett, J.A. Novel role for calcium-independent phospholipase A(2) in the macrophage antiviral response of inducible nitric-oxide synthase expression. J. Biol. Chem. 2002, 277, 38449-38455.

62. Moran, J.M.; Buller, R.M.; McHowat, J.; Turk, J.; Wohltmann, M.; Gross, R.W.; Corbett, J.A. Genetic and pharmacologic evidence that calcium-independent phospholipase A2 $\beta$ regulates virus-induced inducible nitric-oxide synthase expression by macrophages. J. Biol. Chem. 2005, 280, 28162-28168. 
63. Kominato, Y.; Galson, D.; Waterman, W.R.; Webb, A.C.; Auron, P.E. Monocyte expression of the human prointerleukin $1 \beta$ gene (IL1B) is dependent on promoter sequences which bind the hematopoietic transcription factor Spi-1/PU.1. Mol. Cell. Biol. 1995, 15, 58-68.

64. Lodie, T.A.; Savedra, R., Jr.; Golenbock, D.T.; van Beveren, C.P.; Maki, R.A.; Fenton, M.J. Stimulation of macrophages by lipopolysaccharide alters the phosphorylation state, conformation, and function of PU.1 via activation of casein kinase II. J. Immunol. 1997, 158, 1848-1856.

65. Wasylyk, B.; Hagman, J.; Gutierrez-Hartmann, A. Ets transcription factors: nuclear effectors of the Ras-MAP-kinase signaling pathway. Trends Biochem. Sci. 1998, 23, 213-216.

66. Williams, S.D.; Ford, D.A. Calcium-independent phospholipase $\mathrm{A}_{2}$ mediates CREB phosphorylation and c-fos expression during ischemia. Am. J. Physiol. Heart circ. Physiol. 2001, 281, H168-H176.

67. Blair, L.A.; Maggi, L.B., Jr.; Scarim, A.L.; Corbett, J.A. Role of interferon regulatory factor-1 in double-stranded RNA-induced iNOS expression by mouse islets. J. Biol. Chem. 2002, 277, 359-365.

68. Freudenburg, W.; Buller, R.M.; Corbett, J.A. Src family kinases participate in the regulation of encephalomyocarditis virus-induced cyclooxygenase-2 expression by macrophages. J. Gen. Virol. 2010, 91, 2278-2285.

69. Leu, T.H.; Charoenfuprasert, S.; Yen, C.K.; Fan, C.W.; Maa, M.C. Lipopolysaccharide-induced c-Src expression plays a role in nitric oxide and TNF $\alpha$ secretion in macrophages. Mol. Immunol. 2006, 43, 308-316.

70. Stovall, S.H.; Yi, A.K.; Meals, E.A.; Talati, A.J.; Godambe, S.A.; English, B.K. Role of vav1and src-related tyrosine kinases in macrophage activation by CpG DNA. J. Biol. Chem. 2004, 279, 13809-13816.

71. Choi, K.S.; Jun, H.S.; Kim, H.N.; Park, H.J.; Eom, Y.W.; Noh, H.L.; Kwon, H.; Kim, H.M.; Yoon, J.W. Role of Hck in the pathogenesis of encephalomyocarditis virus-induced diabetes in mice. J. Virol. 2001, 75, 1949-1957.

72. Vanhaesebroeck, B.; Leevers, S.J.; Ahmadi, K.; Timms, J.; Katso, R.; Driscoll, P.C.; Woscholski, R.; Parker, P.J.; Waterfield, M.D. Synthesis and function of 3-phosphorylated inositol lipids. Ann. Rev. Biochem. 2001, 70, 535-602.

73. Vanhaesebroeck, B.; Guillermet-Guibert, J.; Graupera, M.; Bilanges, B. The emerging mechanisms of isoform-specific PI3K signalling. Nat. Rev. Mol. Cell Biol. 2010, 11, 329-341.

74. Vanhaesebroeck, B.; Stephens, L.; Hawkins, P. PI3K signalling: The path to discovery and understanding. Nat. Rev. Mol. Cell Biol. 2012, 13, 195-203.

75. Freudenburg, W.; Moran, J.M.; Lents, N.H.; Baldassare, J.J.; Buller, R.M.; Corbett, J.A. Phosphatidylinositol 3-kinase regulates macrophage responses to double-stranded RNA and encephalomyocarditis virus. J. Innate Immun. 2010, 2, 77-86.

76. Tyner, J.W.; Uchida, O.; Kajiwara, N.; Kim, E.Y.; Patel, A.C.; O’Sullivan, M.P.; Walter, M.J.; Schwendener, R.A.; Cook, D.N.; Danoff, T.M.; et al. CCL5-CCR5 interaction provides antiapoptotic signals for macrophage survival during viral infection. Nat. Med. 2005, 11, 1180-1187.

77. Cooray, S. The pivotal role of phosphatidylinositol 3-kinase-Akt signal transduction in virus survival. J. Gen. Virol. 2004, 85, 1065-1076.

78. Ehrhardt, C.; Ludwig, S. A new player in a deadly game: Influenza viruses and the PI3K/Akt signalling pathway. Cell. Microbiol. 2009, 11, 863-871. 
79. Stetson, D.B.; Medzhitov, R. Type I interferons in host defense. Immunity 2006, 25, 373-381.

80. Samuel, C.E. The eIF-2 $\alpha$ protein kinases, regulators of translation in eukaryotes from yeasts to humans. J. Biol. Chem. 1993, 268, 7603-7606.

81. Donnelly, N.; Gorman, A.M.; Gupta, S.; Samali, A. The eIF2 $\alpha$ kinases: Their structures and functions. Cell. Mol. Life Sci. 2013, 70, 3493-3511.

82. Meurs, E.; Chong, K.; Galabru, J.; Thomas, N.S.; Kerr, I.M.; Williams, B.R.; Hovanessian, A.G. Molecular cloning and characterization of the human double-stranded RNA-activated protein kinase induced by interferon. Cell 1990, 62, 379-390.

83. Alexopoulou, L.; Holt, A.C.; Medzhitov, R.; Flavell, R.A. Recognition of double-stranded RNA and activation of NF-kB by Toll-like receptor 3. Nature 2001, 413, 732-738.

84. Kato, H.; Takeuchi, O.; Sato, S.; Yoneyama, M.; Yamamoto, M.; Matsui, K.; Uematsu, S.; Jung, A.; Kawai, T.; Ishii, K.J.; et al. Differential roles of MDA5 and RIG-I helicases in the recognition of RNA viruses. Nature 2006, 441, 101-105.

85. Kato, H.; Takeuchi, O.; Mikamo-Satoh, E.; Hirai, R.; Kawai, T.; Matsushita, K.; Hiiragi, A.; Dermody, T.S.; Fujita, T.; Akira, S. Length-dependent recognition of double-stranded ribonucleic acids by retinoic acid-inducible gene-I and melanoma differentiation-associated gene 5 . J. Exp. Med. 2008, 205, 1601-1610.

86. Pichlmair, A.; Schulz, O.; Tan, C.P.; Rehwinkel, J.; Kato, H.; Takeuchi, O.; Akira, S.; Way, M.; Schiavo, G.; Reis e Sousa, C. Activation of MDA5 requires higher-order RNA structures generated during virus infection. J. Virol. 2009, 83, 10761-10769.

87. Christmann, B.S.; Moran, J.M.; McGraw, J.A.; Buller, R.M.; Corbett, J.A. Ccr5 regulates inflammatory gene expression in response to encephalomyocarditis virus infection. Am. J. Pathol. 2011, 179, 2941-2951.

88. Moran, J.M.; Moxley, M.A.; Buller, R.M.; Corbett, J.A. Encephalomyocarditis virus induces PKR-independent mitogen-activated protein kinase activation in macrophages. J. Virol. 2005, 79, 10226-10236.

89. Iordanov, M.S.; Wong, J.; Bell, J.C.; Magun, B.E. Activation of NF-кB by double-stranded RNA (dsRNA) in the absence of protein kinase $\mathrm{R}$ and RNase $\mathrm{L}$ demonstrates the existence of two separate dsRNA-triggered antiviral programs. Mol. Cell. Biol. 2001, 21, 61-72.

90. Gitlin, L.; Barchet, W.; Gilfillan, S.; Cella, M.; Beutler, B.; Flavell, R.A.; Diamond, M.S.; Colonna, M. Essential role of mda-5 in type I IFN responses to polyriboinosinic:polyribocytidylic acid and encephalomyocarditis picornavirus. Proc. Natl. Acad. Sci. USA 2006, 103, 8459-8464.

91. McCartney, S.A.; Vermi, W.; Lonardi, S.; Rossini, C.; Otero, K.; Calderon, B.; Gilfillan, S.; Diamond, M.S.; Unanue, E.R.; Colonna, M. RNA sensor-induced type I IFN prevents diabetes caused by a $\beta$ cell-tropic virus in mice. J. Clin. Invest. 2011, 121, 1497-1507.

92. Oppermann, M. Chemokine receptor CCR5: Insights into structure, function, and regulation. Cell. Signal. 2004, 16, 1201-1210.

93. Raport, C.J.; Gosling, J.; Schweickart, V.L.; Gray, P.W.; Charo, I.F. Molecular cloning and functional characterization of a novel human CC chemokine receptor (CCR5) for RANTES, MIP-1 $\beta$, and MIP-1 $\alpha$. J. Biol. Chem. 1996, 271, 17161-17166. 
94. Samson, M.; Labbe, O.; Mollereau, C.; Vassart, G.; Parmentier, M. Molecular cloning and functional expression of a new human CC-chemokine receptor gene. Biochemistry 1996, 35, 3362-3367.

95. Alkhatib, G.; Combadiere, C.; Broder, C.C.; Feng, Y.; Kennedy, P.E.; Murphy, P.M.; Berger, E.A. CC CKR5: A RANTES, MIP-1 $\alpha$, MIP-1 $\beta$ receptor as a fusion cofactor for macrophage-tropic HIV-1. Science 1996, 272, 1955-1958.

96. Deng, H.; Liu, R.; Ellmeier, W.; Choe, S.; Unutmaz, D.; Burkhart, M.; di Marzio, P.; Marmon, S.; Sutton, R.E.; Hill, C.M.; et al. Identification of a major co-receptor for primary isolates of HIV-1. Nature 1996, 381, 661-666.

97. Wu, L.; Gerard, N.P.; Wyatt, R.; Choe, H.; Parolin, C.; Ruffing, N.; Borsetti, A.; Cardoso, A.A.; Desjardin, E.; Newman, W.; et al. CD4-induced interaction of primary HIV-1 gp120 glycoproteins with the chemokine receptor CCR-5. Nature 1996, 384, 179-183.

98. Liu, R.; Paxton, W.A.; Choe, S.; Ceradini, D.; Martin, S.R.; Horuk, R.; MacDonald, M.E.; Stuhlmann, H.; Koup, R.A.; Landau, N.R. Homozygous defect in HIV-1 coreceptor accounts for resistance of some multiply-exposed individuals to HIV-1 infection. Cell 1996, 86, 367-377.

99. Samson, M.; Libert, F.; Doranz, B.J.; Rucker, J.; Liesnard, C.; Farber, C.M.; Saragosti, S.; Lapoumeroulie, C.; Cognaux, J.; Forceille, C.; et al. Resistance to HIV-1 infection in caucasian individuals bearing mutant alleles of the CCR-5 chemokine receptor gene. Nature 1996, 382, 722-725.

100. Racaniello, V.R. Cell receptors for picornaviruses. Curr. Top. Microbiol. Immunol. 1990, 161, $1-22$.

101. Bergelson, J.M.; Shepley, M.P.; Chan, B.M.; Hemler, M.E.; Finberg, R.W. Identification of the integrin VLA-2 as a receptor for echovirus 1. Science 1992, 255, 1718-1720.

102. Huber, S.A. VCAM-1 is a receptor for encephalomyocarditis virus on murine vascular endothelial cells. J. Virol. 1994, 68, 3453-3458.

103. Tomassini, J.E.; Graham, D.; DeWitt, C.M.; Lineberger, D.W.; Rodkey, J.A.; Colonno, R.J. cDNA cloning reveals that the major group rhinovirus receptor on HeLa cells is intercellular adhesion molecule 1. Proc. Natl. Acad. Sci. USA 1989, 86, 4907-4911.

104. Floto, R.A.; MacAry, P.A.; Boname, J.M.; Mien, T.S.; Kampmann, B.; Hair, J.R.; Huey, O.S.; Houben, E.N.; Pieters, J.; Day, C.; et al. Dendritic cell stimulation by mycobacterial Hsp70 is mediated through CCR5. Science 2006, 314, 454-458.

105. Bukrinsky, M.I.; Nottet, H.S.; Schmidtmayerova, H.; Dubrovsky, L.; Flanagan, C.R.; Mullins, M.E.; Lipton, S.A.; Gendelman, H.E. Regulation of nitric oxide synthase activity in human immunodeficiency virus type 1 (HIV-1)-infected monocytes: Implications for HIV-associated neurological disease. J. Exp. Med. 1995, 181, 735-745.

106. Lisi, L.; Tramutola, A.; de Luca, A.; Navarra, P.; Russo, C.D. Modulatory effects of the CCR5 antagonist maraviroc on microglial pro-inflammatory activation elicited by gp120. J. Neurochem. 2012, 120, 106-114.

107. Tomkowicz, B.; Lee, C.; Ravyn, V.; Cheung, R.; Ptasznik, A.; Collman, R.G. The Src kinase Lyn is required for CCR5 signaling in response to MIP-1 $\beta$ and R5 HIV-1 gp120 in human macrophages. Blood 2006, 108, 1145-1150. 
108. Cheung, R.; Ravyn, V.; Wang, L.; Ptasznik, A.; Collman, R.G. Signaling mechanism of HIV-1 gp120 and virion-induced IL-1 $\beta$ release in primary human macrophages. J. Immunol. 2008, 180, 6675-6684.

109. Takahashi, T.; Zhu, S.J.; Sumino, H.; Saegusa, S.; Nakahashi, T.; Iwai, K.; Morimoto, S.; Kanda, T. Inhibition of cyclooxygenase-2 enhances myocardial damage in a mouse model of viral myocarditis. Life Sci. 2005, 78, 195-204.

110. Platanias, L.C. Mechanisms of type-I- and type-II-interferon-mediated signalling. Nat. Rev. Immunol. 2005, 5, 375-386.

111. Sadler, A.J.; Williams, B.R. Interferon-inducible antiviral effectors. Nat. Rev. Immunol. 2008, 8 , $559-568$.

(C) 2015 by the authors; licensee MDPI, Basel, Switzerland. This article is an open access article distributed under the terms and conditions of the Creative Commons Attribution license (http://creativecommons.org/licenses/by/4.0/). 